\title{
Critical Aortic Stenosis in the Neonate. Clinical Assessment and Surgical Outcome in 18 Patients
}

\author{
Edmar Atik, Miguel Barbero-Marcial, Elisa R. Iwahashi, Jorge Y. Afiune, Munir Ebaid \\ São Paulo, SP- Brazil
}

Objective - To assess neonates with aortic stenosis with early decompensation operated upon. ( $\mathrm{LCO})(\mathrm{CHF})$.

Methods - A and retrospective study analyzing 6 neonates with LCO, group I (GI), and 12 neonates with CHF, group II (GII). Clinical radiographic, electrocardiographic and echocardiographic findings also provided comparative bases for the study, as did surgical and evolutional findings.

Results - The mean ages at hospitalization and surgery $(p=0.0031)$ were 14.3 and 14.8 days in GI and 35.4 and 42.8 days in GII, respectively. Cardiac murmurs were more intense in $\operatorname{GII}(p=0.0220)$. The aortic ring was smaller in $G I(8.0 \pm 2.5 \mathrm{~mm})$ as compared to $G I I(11.4 \pm 1.4 \mathrm{~mm})(p=$ $0.2882)$. Ventricular function was reduced to $18 \pm 5.5 \%$ and $33.3 \pm 7.6 \%$ in GI and GII, respectively $(p=0.0162)$. Aortic atresia, however, was present only in 2 neonates in GI. Five of 6 patients in GI died but all patients in GII survived $(p=0.0007)$. In the latter group, $84.6 \%$ of the patients were in functional class I (FC-I) in the long-term follow-up, with moderate residual lesions in 6 neonates, discrete residual lesions in 4, and reoperation in 2.

Conclusion-Aortic stenosis is a severe anomaly of the neonate, whose immediate evolution depends on the pre-operative anatomic and functional findings, and the late evolution essentially depends on the anatomic features of the valve.

Key words: aortic stenosis, neonate, congenital heart disease, surgery

Instituto do Coração do Hospital das Clínicas - FMUSP Mailing address: Edmar Atik - Incor - Av. Dr. Enéas C. Aguiar, 44 - 05403-000 São Paulo, SP
Aortic stenosis is a severe congenital defect when it becomes manifest in the neonatal period. Therefore, it remains a challenge due to its high morbidity and mortality rate ${ }^{1-3}$. Intervention is mandatory even though controversy exists in regard to the most adequate treatment: surgery ${ }^{2-6}$ or balloon ${ }^{7-13}$ (table I).

According to a series of experiments, mortality seems to relate more to the unfavorable anatomical type of the left side of the heart, mainly the size of the aortic and mitral rings, the size of the left ventricle (LV), and any associated defects including endocardial fibroelastosis, rather than to the type of treatment chosen ${ }^{1-4,11-13}$.

We provide here short- and long-term outcomes of our experience in the surgical treatment of aortic stenosis, contributing to the literature that shows different results in the use of one or the other type of treatment ${ }^{2-13}$.

\section{Methods}

We retrospectively assessed 18 patients consecutively operated upon at INCOR-FMUSP, over the period from January '90 to December'98. Patients' ages were under 2 months.

According to the clinical findings at the time of surgery, two groups were established: group I (GI) consisting of patients with low cardiac output (LCO), and group II (GII) consisting of patients with congestive heart failure (CHF). GI comprised 6 patients and was characterized by severe dyspnea, discomfort, cyanosis, inadequate peripheral perfusion, weak pulse, blood hypotension, and use of vasoactive drugs, such as dopamine, dobutamine, and prostaglandin E1. GII comprised 12 patients and was characterized by mild tachypnea, no cyanosis, good peripheral perfusion, weak pulse, blood hypotension, and no need for vasoactive drugs.

In each group, general data were analyzed comparatively as were the ages at the moment of the discovery of the heart disease, at hospitalization, and at surgery. We also compared the preponderant symptom, the significant sympclinical data, such as the intensity of the cardiac murmur, and the results of complementary laboratory tests, in addition to the surgical and evolutional findings.

An the electrocardiogram, we studied the QRS electric 


\begin{tabular}{|c|c|c|c|c|c|c|c|c|c|}
\hline Author & & nber & ID & Thrombosis & AoR & Evolution & Restenosis & AoR & $\mathrm{LD}$ \\
\hline Year & Surgery & Balloon Cat & & & & & & & \\
\hline $\begin{array}{l}\text { Gildein } \\
1996\end{array}$ & 33 & - & 6 & - & - & $\begin{array}{c}9 \mathrm{~d}-6 \mathrm{y} \\
8 \mathrm{~m}\end{array}$ & 14 & 1 & 4 \\
\hline $\begin{array}{l}\text { Gaynor } \\
1995\end{array}$ & 61 & 12 & $\begin{array}{c}31 \\
7\end{array}$ & - & - & $8,3 \pm 1,1 \mathrm{y}$ & 12 & 4 & 3 \\
\hline $\begin{array}{l}\text { Gatzoulis } \\
! 995\end{array}$ & 7 & 8 & $\begin{array}{l}2 \\
2\end{array}$ & $\begin{array}{l}- \\
1\end{array}$ & - & $\begin{array}{c}4 m-5 y \\
-\end{array}$ & - & - & - \\
\hline $\begin{array}{l}\text { Weber } \\
1998\end{array}$ & 10 & $13(\mathrm{AC})$ & $\begin{array}{l}1 \\
-\end{array}$ & - & - & $\begin{array}{l}77 \pm 48 \mathrm{~m} \\
16 \pm 15 \mathrm{~m}\end{array}$ & $\begin{array}{l}3 \\
3\end{array}$ & $\begin{array}{l}4 \\
1\end{array}$ & $\begin{array}{l}1 \\
2\end{array}$ \\
\hline $\begin{array}{l}\text { Mosca } \\
1995\end{array}$ & 21 & 9 & $\begin{array}{l}2 \\
1\end{array}$ & - & $\begin{array}{l}4 \\
2\end{array}$ & $\begin{array}{l}56,5 \pm 24,9 \mathrm{~m} \\
37,2 \pm 15,2 \mathrm{~m}\end{array}$ & $\begin{array}{l}4 \\
1\end{array}$ & $\begin{array}{l}4 \\
2\end{array}$ & $\begin{array}{l}1 \\
-\end{array}$ \\
\hline $\begin{array}{l}\text { Egito } \\
1997\end{array}$ & & 33 & 4 & 20 & 4 & $8,3 y$ & 12 & 3 & - \\
\hline $\begin{array}{l}\text { Magee } \\
1997\end{array}$ & & $\begin{array}{l}9(\mathrm{VF}) \\
15(\mathrm{AF})\end{array}$ & - & $\begin{array}{l}1 \\
8\end{array}$ & $\begin{array}{l}2 \\
6\end{array}$ & $\begin{array}{l}\text { No } \\
\text { No }\end{array}$ & & & \\
\hline $\begin{array}{l}\text { Giusti } \\
1995\end{array}$ & & $20(\mathrm{AC})$ & 7 & - & 6 & $2-54 m$ & 3 & 2 & - \\
\hline $\begin{array}{l}\text { Cazzaniga } \\
1998\end{array}$ & & 32 & 8 & - & - & 4 & 4 & 2 & \\
\hline $\begin{array}{l}\text { Piechaud } \\
1995\end{array}$ & & 20 & 4 & - & $6 \quad 37,4 \pm 25 \mathrm{~m}$ & - & 3 & - & \\
\hline
\end{tabular}

axis and the type of ventricular hypertrophy, in addition to in the T wave changes in the left precordial leads. On chest $\mathrm{X}$-ray, the size of the cardiac area was evaluated. On echocardiogram, the aortic ring, the shortening fraction of the cardiac fiber, and the transvalvar aortic pressure gradient were assessed. Evaluations of the sizes of the LV and mitral ring were disregarded because they were considered normal in all patients ( $18 \mathrm{~mm}$ and $14 \mathrm{~mm}$, respectively).

Qualitative variables of the groups of patients with LCO and CHF were compared using Fischer's exact test. Quantitative variables were analyzed with the Student's $t$ test. When data distribution did not approach that which is considered normal, the Wilcoxon's test was used for independent samples. The Statistical Analysis System (SAS) was used for the statistical analysis ${ }^{14}$.

\section{Results}

The male sex predominated in both groups: in GI, 5 (83\%) out of the 6 patients were males, and in GII, 9 (75\%) out of the 12 patients were males. Birth weight was lower in GI, where it varied from 2,000 to $3,950 \mathrm{~g}$ (mean $=2,744 \pm 752.5 \mathrm{~g}$ ), as compared to GII, where it varied from 2,345 to $3,860 \mathrm{~g}$ (mean $=$ $3,028.8 \pm 364.8 \mathrm{~g}$ ). The median of birth weight was $2,505 \mathrm{~g}$ in GI and $3,035 \mathrm{~g}$ in GII ( $\mathrm{p}=0.683-\mathrm{NS})$.

Heart disease manifested itself on the first day of life in 15 out of the 18 patients (all the 6 patients in GI and 9 patients in
GII). The type of manifestation, however, was different because it resulted from the LCO present in 4(67\%) out of the 6 patients in GI and from the cardiac murmur present in the 2 other patients of GI and in 10 (83\%) out of the 12 patients of GII.

The age at hospitalization was lower for the group with LCO, with a mean of $14.3 \pm 18.7$ days, and in 4 out of the 6 patients it was only 2 days, as compared with $35.4 \pm 21.3$ days for the other group $(\mathrm{p}=0.2234-\mathrm{NS})$. Earlier hospitalization is an indication of the major repercussion of the anomaly in the first group.

The same is true for the age at surgery. It was lower in the GI (mean $=14.8 \pm 19.1$ days) and in 4 out of the 6 patients of this group it was only 4 days, as compared to $42.8 \pm 21.5$ days for GII $(p=0.0031)$. The median ages at hospitalization and at surgery were 4.5 and 5.0 days for GI and 36 and 41 days for GII, respectively.

Intensity of the cardiac murmur showed an inverse relationship to the clinical repercussion, and it was proportionally less intense in the patients with $\mathrm{LCO}(\mathrm{p}=0.0220)$ (table II).

Moderate cardiomegaly assessed on chest X-ray was evident in $83.3 \%$ of the patients. Biventricular hypertrophy was found in 7 patients and LV hypertrophy in 8 patients, while right ventricle hypertrophy was found in only 3 . The median of the QRS Axis corresponded to +90 and +100 in the 2 groups $(\mathrm{p}=0.0564)$. The negative $\mathrm{T}$ wave occurred in the left precordial leads in $83 \%$ of the GI and in $17 \%$ of the GII ( $p=0.0430)$. On the echocardiogram, 2 out of the 6 patients in GI with aortic atresia and the unicuspid valve had a small aortic ring of $5 \mathrm{~mm}$. In this group, the mean value 


\begin{tabular}{|c|c|c|c|c|c|c|}
\hline \multirow{3}{*}{ Sex } & & $\operatorname{LCO}(n=6$ & & $\operatorname{CHF}(\mathrm{n}=12)$ & Descriptive level & \\
\hline & Male & 5 & $83 \%$ & 9 & $75 \%$ & $\mathrm{p}=1.0000^{\complement}$ \\
\hline & Female & 1 & $17 \%$ & 3 & $25 \%$ & \\
\hline \multirow[t]{3}{*}{ Age at symptom onset } & $1 \mathrm{~d}$ & 6 & $100 \%$ & 9 & $75 \%$ & \\
\hline & $9-30 \mathrm{~d}$ & - & & 3 & $25 \%$ & \\
\hline & Murmur & 2 & $33 \%$ & 10 & $83 \%$ & \\
\hline \multirow[t]{3}{*}{ Type of symptoms } & Dyspnea & 0 & $0 \%$ & 2 & $17 \%$ & \\
\hline & Low output & 4 & $67 \%$ & 0 & $0 \%$ & \\
\hline & Média (dp) & 2744.2 & $(752.5)$ & 3028.8 & (364.8) & \\
\hline \multirow[t]{3}{*}{ Birth weight (g) } & Median & \multicolumn{2}{|c|}{2505.0} & \multicolumn{2}{|c|}{3035.0} & $\mathrm{p}=0.6873^{\#}$ \\
\hline & Min - Max & 2000.0 & $-3950,0$ & 2345.0 & -3860.0 & \\
\hline & Mean (sd) & 14.3 & (18.7) & 35.4 & $(21.3)$ & \\
\hline \multirow[t]{3}{*}{ Age at hospitalization (d) } & Median & \multicolumn{2}{|c|}{4.5} & \multicolumn{2}{|c|}{36.0} & $\mathrm{p}=0.2234^{\star}$ \\
\hline & Min - Max & 1.0 & -45.0 & 10.0 & -80.0 & \\
\hline & Média (dp) & 14.8 & (19.1) & 42.8 & (21.5) & \\
\hline \multirow[t]{3}{*}{ Age at surgery (d) } & Median & \multicolumn{2}{|c|}{5.0} & \multicolumn{2}{|c|}{41,0} & $\mathrm{p}=0,0031^{\&}$ \\
\hline & Min - Max & 1.0 & -46.0 & 19.0 & -84.0 & \\
\hline & 0 & 1 & $17 \%$ & 0 & $0 \%$ & \\
\hline \multirow[t]{3}{*}{ Cardiac murmur } & + & 3 & $50 \%$ & 1 & $8 \%$ & $\mathrm{p}=0.0220^{\varepsilon}$ \\
\hline & + & 2 & $33 \%$ & 9 & $75 \%$ & \\
\hline & +H+ & 0 & $0 \%$ & 2 & $17 \%$ & \\
\hline
\end{tabular}

of the ring of the 6 patients corresponded to $8.0 \pm 2.5 \mathrm{~mm}$, and in GII it corresponded to $11.4 \pm 1.4 \mathrm{~mm}(\mathrm{p}=0.2882)$.

The transvalvar aortic pressure gradient was equivalent in both groups: $81 \pm 39.9 \mathrm{mmHg}$ and $87.2 \pm 24.3 \mathrm{mmHg}(\mathrm{p}=$ $0.4412-\mathrm{NS})$. The shortening fraction of the myocardial fiber in GI varied from $10 \%$ to $27 \%$, and its mean value $(18.8 \pm 5.5 \%)$ was clearly lower than that of GII $(33.3 \pm 7.6 \%)$, where the values ranged from $18 \%$ to $46 \%(\mathrm{p}=0.0162)$.

According to the significant dysfunctions of the LV in GI, one can infer that the transvalvar aortic pressure gradient is underestimated. Mitral regurgitation occurred in $83 \%$ of the patients in GI and in only $17 \%$ of the patients in GII $(\mathrm{p}=0.0130)$.

Death at surgery occurred in $5(83 \%)$ out of the 6 patients with LCO and the post-operative evolution could be determined in the only survivor of this group and in the other 12 patients with CHF operated upon. From the latter, 10 patients were in functional class I (FC-I) over a follow-up period of 1 month to 8 years (mean $=4.2$ years), and 2 patients were in FC-II. A mild lesion evaluated through the pressure gradient was found in $4(35 \%)$ patients ( mean $=35 \mathrm{mmHg}$ ); a moderate lesion was found in $6(50 \%)$ patients $(\mathrm{mean}=60 \mathrm{mmHg})$; and a marked lesion was detected in $2(17 \%)$ patients (mean $=80$ $\mathrm{mmHg}$ ). These patients required re-operation and showed improvement after a new commissurotomy, and evolved to milder degrees of obstruction (table III).

\section{Discussion}

The reports about experiences with neonates with critical aortic stenosis presented in the literature in a series of publications have stressed the high morbidity and mortality rates of this anomaly that occur irrespective of the type of treatment employed, either surgical ${ }^{2-4}$ or through balloon catheter ${ }^{10-13}$. Published reports have emphasized that mor- tality relates to unfavorable anatomy, mainly small aortic and mitral rings, and the LV hypoplasia and endocardial fibroelastosis ${ }^{1,4,11-13}$.

Our 2 patients with LCO and small aortic ring associated with aortic atresia and hypoplasia of the ascending aorta died. The smallest aortic ring $(8.0 \pm 2.5 \mathrm{~mm})$ in the group of patients with LCO as compared with that of the group of patients with $\mathrm{CHF}(11.4 \pm 1.4 \mathrm{~mm})$ also favored the negative evolution.

Little emphasis in the literature is placed on the functional status of patients as a cause of death. According to our findings, there is a clear relation between the surgical mortality and the significant degree of ventricular dysfunction assessed through the low shortening fraction of the myocardial fiber on the echocardiogram and through the clinical features of the LCO. In these patients, peripheral perfusion is maintained through the use of vasoactive drugs and prostaglandin E1.

Therefore, in the group with LCO and with anatomical findings similar to those in the group with CHF, except 2 cases of aortic atresia and a severe hypoplastic aortic ring, 5 $(83 \%)$ out of the 6 patients died. In GII, all patients survived.

This relation is significant because the only variable was the degree of functional disorder, since the electrocardiographic, radiographic, and anatomic and surgical findings are all very similar in both groups. The negative $\mathrm{T}$ wave in the left precordial leads and the mitral regurgitation, more commonly found in the group with LCO, express the major repercussion of the anomaly in GI.

The earlier decompensation of some patients depends on the magnitude of the repercussion of the defect, which may already be felt during fetal life due to the smaller mean birth weight seen in the group with LCO. This group also showed a lower age at hospitalization and, mainly, at surgery.

The hemodynamic instability of this more critical 


\begin{tabular}{|c|c|c|c|c|c|c|c|}
\hline \multirow{3}{*}{$\begin{array}{l}\text { Chest X-ray } \\
\text { Cardiac area }\end{array}$} & \multirow{3}{*}{$\begin{array}{l}\text { Normal } \\
\text { Enlarged }\end{array}$} & \multicolumn{3}{|c|}{$\mathrm{LCO}(\mathrm{n}=6)$} & \multicolumn{2}{|c|}{ CHF $(n=12)$} & \multirow{3}{*}{$\begin{array}{c}\text { Descriptive level } \\
\qquad p=1.0000^{f}\end{array}$} \\
\hline & & \multirow{2}{*}{$\begin{array}{l}1 \\
5\end{array}$} & & \multirow{2}{*}{$\begin{array}{l}17 \% \\
83 \%\end{array}$} & \multirow{2}{*}{$\begin{array}{c}2 \\
10\end{array}$} & \multirow{2}{*}{$\begin{array}{l}17 \% \\
83 \%\end{array}$} & \\
\hline & & & & & & & \\
\hline Electrocardiogram & Mean (sd) & 93,3 & & $(36.2)$ & 100.0 & (23.7) & \\
\hline \multirow[t]{2}{*}{ QRS axis $\left(^{\circ}\right)$} & Median & \multirow{2}{*}{\multicolumn{2}{|c|}{90.0}} & & \multicolumn{2}{|c|}{100.0} & $\mathrm{p}=0.0564^{\#}$ \\
\hline & Min-Max & & & -160.0 & 80.0 & -170.0 & \\
\hline \multirow[t]{3}{*}{ Overloads } & $\mathrm{RV}$ & 2 & & $33 \%$ & 1 & $8 \%$ & \multirow{3}{*}{$\mathrm{p}=0.2930^{\mathrm{e}}$} \\
\hline & LV & 3 & & $50 \%$ & 5 & $42 \%$ & \\
\hline & Biventricular & 1 & & $17 \%$ & 6 & $50 \%$ & \\
\hline \multicolumn{2}{|l|}{ Negative T wave V4-6 } & \multicolumn{2}{|l|}{5} & $83 \%$ & 2 & $17 \%$ & $\mathrm{p}=0.0430^{£}$ \\
\hline \multirow{3}{*}{$\begin{array}{l}\text { Echocardiogram } \\
\text { Aortic ring }\end{array}$} & Mean (sd) & 8.0 & & (2.5) & 11.4 & (1.4) & \\
\hline & Median & \multirow{2}{*}{\multicolumn{2}{|c|}{9.0}} & & \multicolumn{2}{|c|}{11.0} & $\mathrm{p}=0.2882^{\#}$ \\
\hline & $\operatorname{Min}-\operatorname{Max}$ & & & -10.0 & 10.0 & -14.0 & \\
\hline \multirow[t]{3}{*}{$\Delta \mathrm{D}$} & Mean (sd) & 18.8 & & (5.5) & 33.3 & (7.6) & \\
\hline & Median & \multirow{2}{*}{\multicolumn{2}{|c|}{18.5}} & & \multicolumn{2}{|c|}{31.5} & $\mathrm{p}=0.0162^{\&}$ \\
\hline & Min - Max & & & -27.0 & 18.0 & -46.0 & \\
\hline \multirow[t]{3}{*}{ Pressure gradient } & Mean (sd) & \multirow{2}{*}{\multicolumn{3}{|c|}{70.5}} & 87.2 & (24.3) & \\
\hline & Median & & & & \multirow{2}{*}{\multicolumn{2}{|c|}{80.0}} & $\mathrm{p}=0.4412^{\#}$ \\
\hline & $\operatorname{Min}-\operatorname{Max}$ & 48.0 & -152.0 & 57.0 & & & \\
\hline \multicolumn{2}{|l|}{ Mitral regurgitation } & \multicolumn{2}{|l|}{5} & $83 \%$ & 2 & $17 \%$ & $\mathrm{P}=0.0130^{£}$ \\
\hline \multirow[t]{5}{*}{ Valvar anatomy } & Bicuspid valve & 3 & & $50 \%$ & 8 & $67 \%$ & \\
\hline & Tricuspid valve & 1 & & $17 \%$ & 2 & $17 \%$ & $\mathrm{p}=0.7870^{\mathfrak{f}}$ \\
\hline & Unicuspid valve & 2 & & $33 \%$ & 2 & $17 \%$ & \\
\hline & Valve Atresia & 2 & & $33 \%$ & 0 & $0 \%$ & $\mathrm{p}=0,0980^{£}$ \\
\hline & Valve Buddings & 2 & & $33 \%$ & 2 & $17 \%$ & $\mathrm{p}=0,5690^{\mathrm{f}}$ \\
\hline Outcome & Death & 5 & $83 \%$ & 0 & & & $\mathrm{p}=0.0007^{\mathfrak{e}}$ \\
\hline & Period & $2 \mathrm{~m}$ & & $1 \mathrm{~m}$ & $-8 \mathrm{a}$ & & \\
\hline & FC-I & 1 & & $17 \%$ & 10 & $75 \%$ & \\
\hline Reestenose & Mild & 1 & & $17 \%$ & 4 & $35 \%$ & \\
\hline & Moderate & 0 & & $0 \%$ & 6 & $50 \%$ & \\
\hline & Marked & 0 & & $0 \%$ & 2 & $17 \%$ & \\
\hline
\end{tabular}

group is such that the mechanisms of cardiac compensation fail, with a low threshold of significant modifications, even to minimally invasive procedures, to the anesthetic induction itself, and to alterations in environmental temperature. Any of those situations may trigger severe arrhythmias, such as ventricular fibrillation, and even cardiac arrest.

This is why the literature also reports such a high mortality rate for this group of patients undergoing interventionist therapy through dilation with balloon catheters. Considering the severity of the situation, the ideal management of these patients may be the most precocious intervention possible, still in the first hours of life. This management may be foreseen and programmed through prenatal echocardiographic assessment, aided by evaluation of low fetal body weight, which is an expression of the systemic LCO in intrauterine life.

Even though the group of patients with CHF showed a good evolution in the long run, surgical reintervention was required in 2 out of the 12 patients. It may be required in the near future in an additional 6 out of the 12 patients because they already show moderate aortic restenosis with a mean transaortic pressure gradient of $60 \mathrm{mmHg}$. This occurred in the group operated upon and in the other that underwent dilation through balloon catheter, according to studies already published ${ }^{2,3,5,6,9,11}$.

The risk of aortic regurgitation may be higher in the group undergoing the interventionist procedure through balloon catheter, but general evolution has been shown to be similar for both therapeutic managements ${ }^{3,5,6,7,9,11-13}$.

After the neonatal period some features, such as aortic restenosis, aortic regurgitation, arrhythmias, and syncopes occurring in patients who underwent either surgery or balloon catheter dilation, increase long-term morbidity ${ }^{2,3,5-7,9,11-13}$. The reintervention indices are high in any of the procedures, corroborating the severity of the valvar anomaly that becomes manifest in the neonatal period. In addition to the marked dysfunction, the morphological substrate of this anomaly that significantly influences the immediate evolution in the neonatal period 
includes patients with aortic annular hypoplasia, valvar dysplasia, LV hypoplasia, mitral anomalies, and endocardial fibroelastosis.

In our service, we have chosen the surgical approach for all these anatomical changes, but we do not criticize management with cardiac catheterization, except in the case of aortic regurgitation, which may be an aggravating evolutional factor.

\section{Acknowledgements}

We thankDália Ballas Wajsbrot for the statistical analysis.

\section{References}

1. Rhodes L, Colan S, Perry S, Jonas R, Sanders S. Predictors of survival in neonates with critical aortic stenosis. Circulation 1991; 84: 2325-35.

2. Gildein HP, Kleinert S, Weintraub RG, Wilkinson JL, Karl TR, Mee RB. Surgical commissurotomy of the aortic valve: outcome of open valvotomy in neonates with critical aortic stenosis. Am Heart J 1996; 131: 754-9.

3. Gaynor JW, Bull C, Sullivan ID, et al. Late outcome of survivors of intervention for neonatal aortic valve stenosis. Ann Thorac Surg 1995; 60: 122-5.

4. Gatzoulis MA, Rigby ML, Shinebourne EA, Redington AN. Contemporary results of balloon valvuloplasty and surgical valvotomy for congenital aortic stenosis. Arch Dis Child 1995; 73: 66-9.

5. Weber HS, Mart CR, Kupferschmid J, Myers JL, Cyran SE. Transcarotid balloon valvuloplasty with continuous transesophageal echocardiographic guidance for neonatal critical aortic valve stenosis: an alternative to surgical palliation. Pediatr Cardiol 1998; 19: 212-17.

6. Mosca R, Iannettoni M, Schwartz S, et al. Critical aortic stenosis in the neonate. A comparison of balloon valvuloplasty and transventricular dilatation. J Thorac Cardiovasc Surg 1995; 109: 147-54.

7. Lababidi Z, Wu J, Walls T. Percutaneous balloon aortic valvuloplasty: results in 23 patients. Am J Cardiol 1984; 53: 194-7.
8. Lababidi Z, Winhaus L. Successful balloon valvuloplasty for neonatal critical aortic stenosis. Am Heart J 1986; 112: 913-16.

9. Egito ES, Moore P, O'Sullivan J, et al. Transvascular balloon dilation for neonatal critical aortic stenosis: early and midterm results. J Am Coll Cardiol 1997; 29: 442-7.

10. Magee AG, Nykanen D, McCrindle BW, Wax D, Freedom RM, Benson LN. Balloon dilation of severe aortic stenosis in the neonate: comparison of anterograde and retrograde catheter approaches. J Am Coll cardiol 1997; 30: 1061-6.

11. Giusti S, Borghi A, Radaelli S, et al. The carotid arterial approach for balloon dilation of critical aortic stenosis in neonates. Immediate results and follow-up. Cardiol Young 1995; 5: 155-60.

12. Cazzaniga M, Fernandez Pineda L, Abraira V, et al. Clinical and echocardiographic impact of neonatal aortic valvuloplasty. Rev Esp Cardiol 1998; 51: 141-51.

13. Piechaud J, Delogu D, Kachaner J, Sidi D. Transcatheter valvotomy of aortic stenosis with dilated left ventricle in the newborns: long term results. J Am Coll Cardiol 1995; 25: 99A.

14. Rosner B. Fundamentals of Bioestatistics. ( $2^{\text {nd }}$ ed.). Boston: PWS Publishers, 1986. 